www.nature.com/ja

\title{
Nocardithiocin, a novel thiopeptide antibiotic, produced by pathogenic Nocardia pseudobrasiliensis IFM 0757
}

\author{
Akira Mukai $^{1}$, Toshio Fukai ${ }^{2,5}$, Yasutaka Hoshino ${ }^{3}$, Katsukiyo Yazawa ${ }^{1}$, Ken-ichi Harada ${ }^{4}$ and Yuzuru Mikami ${ }^{1}$ \\ Nocardithiocin is a novel thiopeptide compound produced by the pathogenic Nocardia pseudobrasiliensis strain IFM 0757. \\ It shows a strong activity against acid-fast bacilli such as the Mycobacterium and Gordonia species. Nocardithiocin was highly \\ active against rifampicin-resistant as well as -sensitive Mycobacterium tuberculosis strains, and most of the resistant strains \\ were inhibited at concentrations ranging from 0.025 to $1.56 \mu \mathrm{g} \mathrm{ml}^{-1}$. The structure of the thiopeptide antibiotic containing \\ thiazole, natural and unnatural amino acids was elucidated by MS and NMR spectral analyses.
}

The Journal of Antibiotics (2009) 62, 613-619; doi:10.1038/ja.2009.90; published online 11 September 2009

Keywords: Nocardia; nocardithiocin; pathogenic actinomycetes; rifampicin-resistant mycobacteria; thiopeptide

\section{INTRODUCTION}

Actinomycetes produce numerous secondary metabolites including various biologically active compounds such as antimicrobial, cytotoxic, immunosuppressive and antifungal agents. ${ }^{1}$ As the potential to isolate useful new antibiotics from Streptomyces sp. is now low and diminishing all the time, we have focused our attention on other sources. Pathogenic actinomycetes are distributed on a limited basis in the natural environment and are difficult to isolate. They can be considered among the rare actinomycetes and represent a relatively unexplored resource for the discovery of new bioactive compounds. We have collected many pathogenic actinomycetes from clinical materials, which mainly belong to the genus of Nocardia and may cause human infections called nocardiosis. ${ }^{2,3}$ They have produced several biologically active compounds such as antitumor and immunosuppressive ones. ${ }^{4,5}$

During our ongoing research for new metabolites from a Nocardia strain (IFM 0757 strain) obtained from a patient at the Health Center, University of Texas, we isolated a new cyclic thiopeptide antibiotic with potent antibacterial activity against rifampicin-resistant $\mathrm{Myco-}$ bacterium tuberculosis, called nocardithiocin (Figure 1), which was classified as a 'series $d$ ' group peptide antibiotic based on the definition by Bagley et al. ${ }^{6}$ Cyclic thiopeptides are known as activators of thiostrepton-induced protein $\mathrm{A}$, which is a member of the mercury resistance regulator family, and are active against Gram-positive bacteria. ${ }^{3,7}$ In this paper, we describe the fermentation, isolation, structure elucidation and antimicrobial activities of the antibiotic.

\section{RESULTS}

Isolation

The separation of the active compounds was monitored by the antimicrobial activity against Corynebacterium xerosis IFM 2057.8 After incubation, the culture broth was centrifuged at 3000 r.p.m. for $10 \mathrm{~min}$. Six hundred milliliters of $\mathrm{MeOH}$ was then added to the mycelial cake and stirred for 3 hours. The $\mathrm{MeOH}$ fraction was filtered, evaporated to dryness and suspended in distilled water. The active compound was then extracted with EtOAc. The compound was further purified by HPLC. The isolation was carried out under dark conditions because the antibiotic was not stable in the light.

\section{Structure elucidation}

The physicochemical data for nocardithiocin are shown in Table 1. The positive ion FAB mass spectrum (JMS-AX500) of nocardithiocin showed a protonated molecule $[\mathrm{M}+\mathrm{H}]^{+}$at $\mathrm{m} / \mathrm{z}$ 1161. HRFAB-MS (JMS-HX110) displayed the $[\mathrm{M}+\mathrm{K}]^{+}$ion at $\mathrm{m} / z 1199.1469$ (calcd. 1199.1527). The molecular formula was determined to be $\mathrm{C}_{48} \mathrm{H}_{48} \mathrm{~N}_{12} \mathrm{O}_{11} \mathrm{~S}_{6}$ based on the HRFAB-MS data by considering the number of protons and carbons from the NMR spectra. In the ${ }^{1} \mathrm{H}$-NMR spectrum, one singlet and four doublet signals assigned to five methyl groups were observed between $\delta 0.86-1.78$, and two singlet signals ( $\delta 3.70$ and 3.97$)$ were assigned to methoxyl groups. Amino acid moiety $\alpha$-proton signals were also observed at $\delta 4.52$ (H-46), 5.11 $(\mathrm{H}-32)$ and $5.56(\mathrm{H}-22)$. Thirteen $s p^{2}$ proton signals and amido proton signals were detected between $\delta$ 8.06-9.52. The ${ }^{13} \mathrm{C}-\mathrm{NMR}$ spectrum showed 48 signals that were assigned to eight methyl, 15

${ }^{1}$ Medical Mycology Research Center, Chiba University, Chuo-ku, Chiba, Japan; ${ }^{2}$ School of Pharmaceutical Sciences, Toho University, Funabashi, Chiba, Japan; ${ }^{3}$ Department of Bioactive Molecules, National Institute of Infectious Diseases, Shinjuku-ku, Tokyo, Japan and ${ }^{4}$ Graduate School of Environmental and Human Science \& Faculty of Pharmacy, Meijo University, Tempaku, Nagoya, Japan

${ }^{5}$ Current address: Department of Health Pharmacy, Yokohama College of Pharmacy, 601 Matano-cho, Totsuka-ku, Yokohama, Kanagawa 245-0066, Japan

Correspondence: Dr K-i Harada, Graduate School of Environmental and Human Science \& Faculty of Pharmacy, Meijo University, Tempaku, Nagoya 468-8503, Japan.

E-mail: kiharada@ccmfs.meijo-u.ac.jp

Received 18 June 2009; revised 13 August 2009; accepted 13 August 2009; published online 11 September 2009 


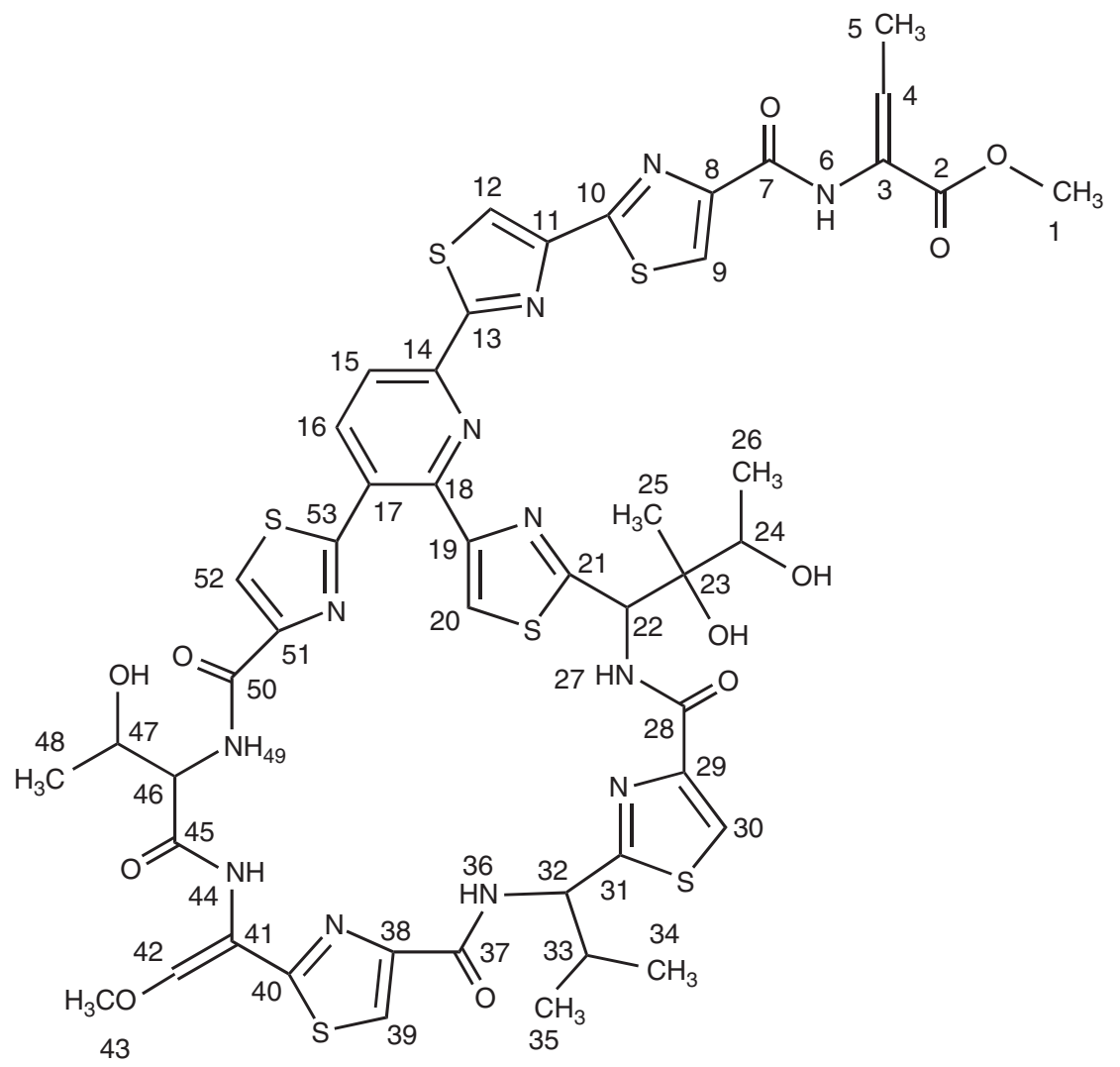

Figure 1 Structure of nocardithiocin.

\section{Table 1 The physicochemical data of nocardithiocin}

\begin{tabular}{ll}
\hline Appearance & White powder \\
Molecular weight & 1160 \\
Molecular formula & $\mathrm{C}_{48} \mathrm{H}_{48} \mathrm{~N}_{12} \mathrm{O}_{11} \mathrm{~S}_{6}$ \\
& \\
HRFAB-MS (m/z) & \\
$\quad$ Found: & $1199.1469[\mathrm{M}+\mathrm{K}]^{+}$ \\
Calcd.: & 1199.1527 \\
& \\
IR $\lambda_{\max }\left(\mathrm{CHCl}_{3}\right)$ & $3728,3699,3628,3596$, \\
& $3383,3113,2961,2269$, \\
& $1665,1533,1477,1273$, \\
& $1236,1273,1236,1148$, \\
& $1067,743,675$ \\
{$[\alpha]_{D}\left(23.2^{\circ} \mathrm{C}, \mathrm{MeOH}\right)$} & $+34.0^{\circ}\left(\mathrm{c} 1 \mathrm{mg} \mathrm{ml} \mathrm{I}^{-1}, \mathrm{MeOH}\right)$ \\
$\mathrm{UV} \lambda_{\max }(\mathrm{MeOH}) \mathrm{nm}(\log \varepsilon)$ & $344.5(3.89), 339.5(3.97)$, \\
& $232.0(4.25)$ \\
\hline
\end{tabular}

methine, and 25 quaternary carbons by heteronuclear multiple quantum coherence and distortionless enhancement by polarization transfer experiments (Table 2). The $\mathrm{C}-\mathrm{H}$ connectivity and assignment of the signals were confirmed by $2 \mathrm{D}$ NMR experiments using ${ }^{1} \mathrm{H}-{ }^{1} \mathrm{H}$ COSY and heteronuclear multiple bond coherence (HMBC) techniques as follows:

\section{Thiazole units}

The thiazole units were contained in substructures B, C and D (Figure 2), and the whole structure was deduced by comparison with those of the corresponding ${ }^{1} \mathrm{H}$ and ${ }^{13} \mathrm{C}$ chemical shifts with those reported for promoinducin, ${ }^{9}$ nocathiacins ${ }^{10}$ and radamycin. ${ }^{11}$ As a result, six thiazole units were determined by the following longrange correlations; in the $\mathrm{HMBC}$ spectrum, the thiazole ring proton signal at $\delta 8.43$ (H-9) showed long-range couplings to carbons at $\delta 149.8$ (C-10) and 161.5 (C-8), H-12 signal at $\delta 8.56$ to $\delta 149.2$ (C$11)$ and $168.2(\mathrm{C}-13), \mathrm{H}-20$ signal at $\delta 8.15$ to $\delta 151.6(\mathrm{C}-19)$ and 169.0 (C-21), H-30 signal at $\delta 8.22$ to $\delta 149.1$ (C-29) and $\delta 170.3$ (C31), H-39 signal at $\delta 8.24$ to 146.7 (C-38) and 160.3 (C-40), and H-52 signal at $\delta 8.14$ to $\delta 149.2(\mathrm{C}-51)$ and 163.5 (C-53).

\section{Substructure A}

Substructure A was a terminal moiety of the side chain (Figure 2). In the COSY spectrum, $\mathrm{CH}_{3}-5(\delta$ 1.78) correlated with the olefinic proton at $\delta 6.76(\mathrm{H}-4)$ and showed a long-range correlation to the quaternary carbon at $\delta 127.3$ (C-3). Furthermore, in the HMBC spectrum, the $\mathrm{H}-4$ proton showed a long-range correlation to the carbonyl carbon at $\delta 164.3$ (C-2), which showed a long-range correlation from the $O$-methyl proton at $\delta 3.70\left(\mathrm{CH}_{3}-1\right)$. An amide proton (disappearing with the addition of $\mathrm{CD}_{3} \mathrm{OD}$ ) at $\delta 9.52$ $(\mathrm{H}-6)$ was correlated to $\mathrm{C}-2$ and $\mathrm{C}-4$, indicating the presence of substructure A.

\section{Substructure B}

Substructure B contained a pyridine ring and four thiazole rings. The ortho-coupled aromatic protons at $\delta 8.34$ (H-15) and 8.53 (H-16), respectively, were connected by the COSY spectrum. H-16 showed long-range correlations to $\delta 149.6(\mathrm{C}-14)$ and 150.9 (C-18), and a long-range coupling from $\mathrm{H}-15$ to $\delta 128.6$ (C-17) was observed. These data revealed the presence of a pyridine ring. The methyl proton signal at $\delta 1.00(\mathrm{H}-26)$ showed long-range couplings to the oxygenated 
Table $2{ }^{1} \mathrm{H}$ and ${ }^{13} \mathrm{C}$ NMR spectral data of nocardithiocin in DMSO- $d_{6}$

\begin{tabular}{|c|c|c|c|c|c|}
\hline Position & $\delta c$ & $\delta_{H}, J(H z)$ & Position & $\delta c$ & $\delta_{H}, J(H z)$ \\
\hline 1 & 51.7 & $3.70(\mathrm{~s})$ & 27 & & $8.17(d, 9.5)$ \\
\hline 2 & 164.3 & & 28 & 159.9 & \\
\hline 3 & 127.3 & & 29 & 149.1 & \\
\hline 4 & 134.0 & $6.76(q, 7)$ & 30 & 124.2 & $8.22(\mathrm{~s})$ \\
\hline 5 & 13.6 & $1.78(\mathrm{~s})$ & 31 & 170.3 & \\
\hline 6 & & $9.52(\mathrm{~s})$ & 32 & 55.5 & $5.11(\mathrm{dd}, 8,0.5)$ \\
\hline 7 & 158.9 & & 33 & 31.0 & $2.65(\mathrm{~m})$ \\
\hline 8 & 161.5 & & 34 & 17.8 & $0.88(d, 7)$ \\
\hline 9 & 125.4 & $8.43(\mathrm{~s})$ & 35 & 19.6 & $0.86(d, 7)$ \\
\hline 10 & 149.8 & & 36 & & $8.48(d, 9.5)$ \\
\hline 11 & 149.2 & & 37 & 160.1 & \\
\hline 12 & 121.5 & $8.56(\mathrm{~s})$ & 38 & 146.7 & \\
\hline 13 & 168.2 & & 39 & 124.0 & $8.24(\mathrm{~s})$ \\
\hline 14 & 149.6 & & 40 & 160.3 & \\
\hline 15 & 118.5 & $8.34(d, 8)$ & 41 & 111.5 & \\
\hline 16 & 140.1 & $8.53(d, 8)$ & 42 & 152.0 & $7.30(\mathrm{~s})$ \\
\hline 17 & 128.6 & & 43 & 61.6 & 3.97 (s) \\
\hline 18 & 150.9 & & 44 & & $9.33(\mathrm{~s})$ \\
\hline 19 & 151.6 & & 45 & 169.8 & \\
\hline 20 & 121.7 & $8.15(\mathrm{~s})$ & 46 & 58.7 & 4.52 \\
\hline 21 & 169.0 & & 47 & 66.9 & $4.36(\mathrm{~m})$ \\
\hline 22 & 54.9 & $5.56(d, 9.5)$ & $\mathrm{OH}$ & & $5.21(\mathrm{~d}, 6)$ \\
\hline 23 & 75.2 & & 48 & 20.0 & $1.27(\mathrm{~d}, 6)$ \\
\hline $\mathrm{OH}$ & & $4.37(\mathrm{~s})$ & 49 & & $8.06(\mathrm{~d}, 8)$ \\
\hline 24 & 69.5 & $3.66(\mathrm{~m}, 6)$ & 50 & 160.1 & \\
\hline $\mathrm{OH}$ & & $4.52(d, 5.5)$ & 51 & 149.2 & \\
\hline 25 & 19.5 & $0.90(\mathrm{~s})$ & 52 & 125.9 & $8.14(\mathrm{~s})$ \\
\hline 26 & 17.2 & $1.00(\mathrm{~d}, 6.5)$ & 53 & 163.5 & \\
\hline
\end{tabular}

methine carbon at $\delta 69.5$ (C-24) and oxygenated quaternary carbon at $\delta 75.2$ (C-23). Moreover, long-range correlations from the methyl proton signal at $\delta 0.90\left(\mathrm{CH}_{3}-25\right)$ to $\mathrm{C}-23, \mathrm{C}-24$ and $\mathrm{C}-22(\delta 54.9)$ were observed. The methine proton at $\delta 5.56(\mathrm{H}-22)$ was coupled to an amide proton at $\delta 8.17$ ( $\mathrm{H}-27)$ and showed a long-range correlation to $\delta 169.0$ (C-21), which was a part of the thiazole unit, indicating the presence of the thiostreptin unit. ${ }^{12}$ The proton signal of the thiazole unit at $\delta 8.15(\mathrm{H}-20)$ showed long-range coupling to $\delta 150.9$ (C-18), which was $\mathrm{C}-2$ of the pyridine unit. Furthermore, long-range coupling from the proton signal of the pyridine unit at $\delta 8.53(\mathrm{H}-16)$ to the quaternary carbon of the thiazole unit at $\delta 163.5$ (C-53), and from $\mathrm{H}-15$ at $\delta 8.34$ to $\delta 168.2$ (C-13) was observed. The presence of the long-range couplings from the proton signal of the third thiazole unit at $\delta 8.56(\mathrm{H}-12)$ to $\delta 149.8(\mathrm{C}-10), \mathrm{H}-9(\delta$ 8.43) to the carbonyl carbon at $\delta 158.9$ (C-7), and from the olefinic proton of the fourth thiazole unit at $\delta 8.14$ (H-52) to the carbonyl carbon at $\delta 160.1$ (C-50) indicated the presence of substructure $B$.

\section{Substructure C}

In the COSY spectrum, vicinal coupling signals were detected between the methyl protons at $\delta 0.86\left(\mathrm{CH}_{3}-35\right) / \delta 0.88\left(\mathrm{CH}_{3}-34\right)$ and the methine proton at $\delta 2.65(\mathrm{H}-33), \mathrm{H}-33$ and the methine proton at $\delta 5.11$ (H-32), and the $\mathrm{H}-32$ and the amide proton at $\delta 8.48$ (H-36). Furthermore, the HMBC spectrum revealed the presence of substructure $\mathrm{C}$ by the long-range correlations from $\mathrm{CH}_{3}-35$ to the methyl carbon at $\delta 17.8$ (C-34), H-32 to a quaternary carbon of the thiazole ring at $\delta 170.3(\mathrm{C}-31)$, and $\mathrm{H}-30$ to the carbonyl carbon at $\delta 159.9$ (C-28).

\section{Substructure D}

Substructure D was determined by the HMBC spectrum, which showed long-range coupling from an oxygenated methyl proton at $\delta$ $3.97\left(\mathrm{H}_{3}-43\right)$ to an olefinic carbon at $\delta 152.0$ (C-42), and long-range correlations from the olefinic proton at $\delta 7.30(\mathrm{H}-42)$ to a quaternary carbon of the thiazole ring at $\delta 160.3(\mathrm{C}-40)$ and an olefinic carbon at $\delta 111.5(\mathrm{C}-41)$, an amide proton at $\delta 9.33(\mathrm{H}-44)$ to $\mathrm{C}-42$, and the olefinic proton of the thiazole ring at $\delta 8.24(\mathrm{H}-39)$ to $\delta 160.1$ (C-37).

\section{Substructure E}

Vicinal coupling signals in the COSY spectrum were observed between the methyl group at $\delta 1.27(\mathrm{H}-48)$ and the methine proton at $\delta 4.36$ $(\mathrm{H}-47), \mathrm{H}-47$ and the hydroxy proton at $\delta 5.21$, the methine proton at $\delta 4.52(\mathrm{H}-46)$ and $\mathrm{H}-46$ and an amide proton at $\delta 8.06(\mathrm{H}-49)$. The long-range couplings in the $\mathrm{HMBC}$ spectrum from $\mathrm{CH}_{3}-48$ to C-46 and $\mathrm{H}-46$ to a carbonyl carbon at $\delta 169.8(\mathrm{C}-45)$ revealed the presence of the threonine moiety in Substructure E.

Finally, each substructure was connected by the long-range correlations of the $\mathrm{HMBC}$ technique from the amide proton $(\mathrm{H}-6)$ to the carbonyl carbon (C-7), H-22 to C-28, H-32 to C-37, H-44 to C-45 and $\mathrm{H}-49$ to $\mathrm{C}-50$. Thus, the planar structure of nocardithiocin was determined as shown in Figure 1 and the ${ }^{1} \mathrm{H}$ and ${ }^{13} \mathrm{C}-\mathrm{NMR}$ spectral data of nocardithiocin are summarized in Table 2.

\section{Stereochemistry}

To determine the absolute configurations of substructures $\mathrm{C}$ and $\mathrm{E}$, the advanced Marfy method ${ }^{13,14}$ was performed. Nocardithiocin was first hydrolyzed with $6 \mathrm{M} \mathrm{HCl}$ and the liberated threonine (substructure E) and the valine-derived thiazole moiety (substructure $\mathrm{C}$ ) were derivatized with 1-fluoro-2,4-dinitrophenyl-5-L-leucineamide (L-FDLA) and D-FDLA. Figure 3 shows the HPLC chromatograms of the 2,4dinitrophenyl-5-L-leucineamide (DLA) derivatives ((A) with L-FDLA and (B) with D-FDLA) of the hydrolyzate. Two desired peaks were observed together with large amounts of the residual reagent and related compounds $\left(^{*}\right)$. Furthermore, an intense peak was also found at around $4 \mathrm{~min}$. These derivatives were also analyzed by LC/MS at $\mathrm{m} /$ $z 414$ and 459 in the positive ion mode (Figure 4). ${ }^{15}$ Using the DL-FDLA method, ${ }^{16}$ it was possible to conclude that the two amino acids have the $\mathrm{L}$ configuration. It was also found that the intense peak observed at around 4 min shown in Figure 3 has a molecular weight of 616. The geometries of the double bonds in substructures A and D and the absolute configuration of substructure B could not be determined in this study.

\section{Antimicrobial activity}

Nocardithiocin showed a strong antimicrobial activity against acidfast bacteria but its activity against other Gram-positive microorganisms was moderate. The MIC values of the antibiotic against Corynebacterium xerosis and Gordonia bronchialis were $<0.0078$ and $0.039 \mu \mathrm{g} \mathrm{ml}^{-1}$, respectively (Table 3 ). As shown in Table 4 , nocardithiocin showed a strong antimicrobial activity against the rifampicin-resistant strains of M. tuberculosis as well as the susceptible ones, and their MIC values were $0.025-6.25 \mu \mathrm{g} \mathrm{ml}^{-1}$ and $0.025-$ $>6.25 \mu \mathrm{g} \mathrm{ml}^{-1}$, respectively. In the comparison of the antimicrobial activity of nocardithiocin with the reference drug of levofloxacin against rifampicin-susceptible as well as rifampicin-resistant mycobacteria, nocardithiocin was found to show an activity higher than that of levofloxacin. Nocardithiocin did not show any antimicrobial activities against gram-negative bacteria and fungi (Table 3). The cytotoxicity of nocardithiocin against LH-60 was $64 \mu \mathrm{g} \mathrm{ml}^{-1}$ (data not shown). 


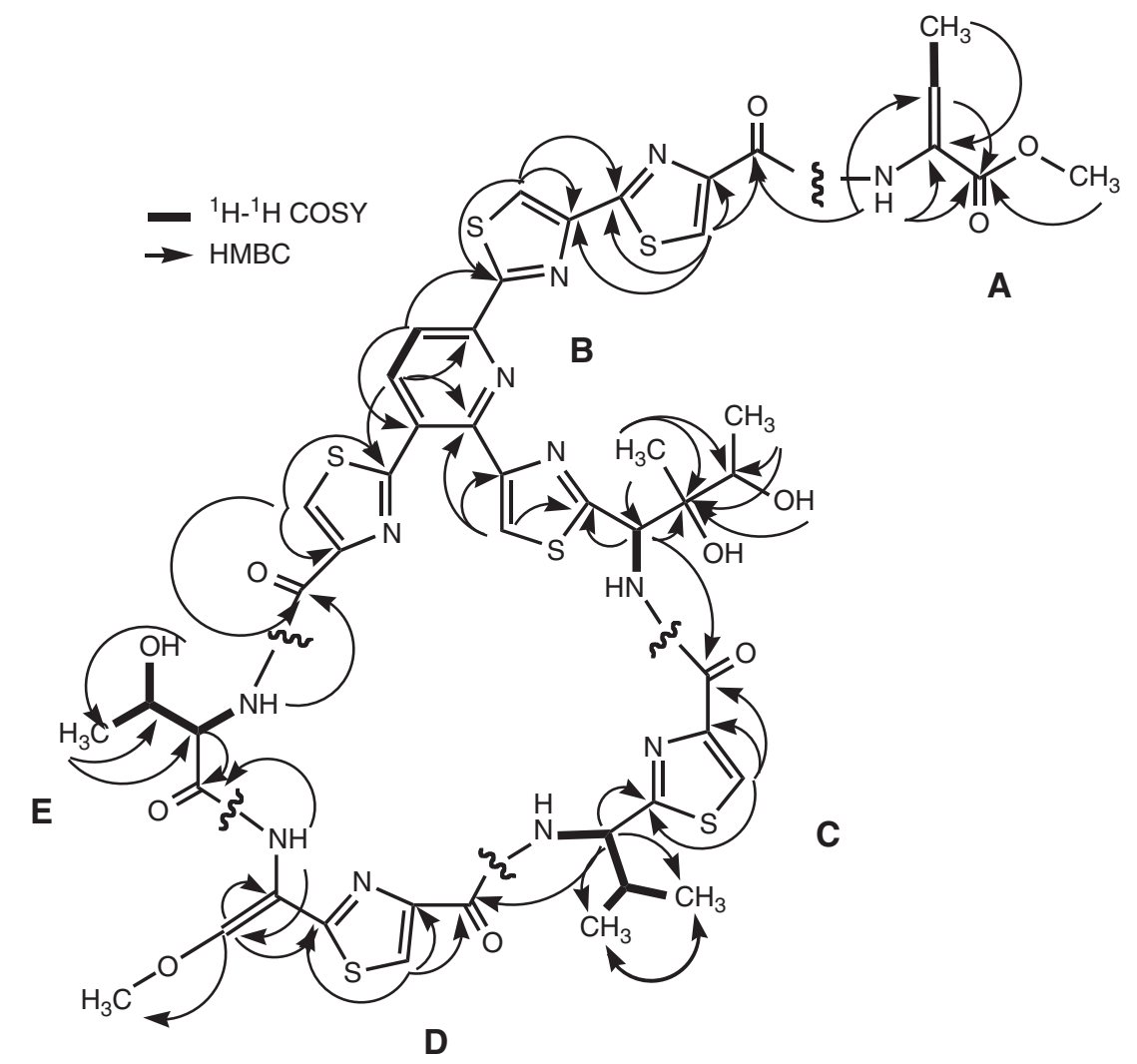

Figure 2 COSY and HMBC correlations of nocardithiocin.

a

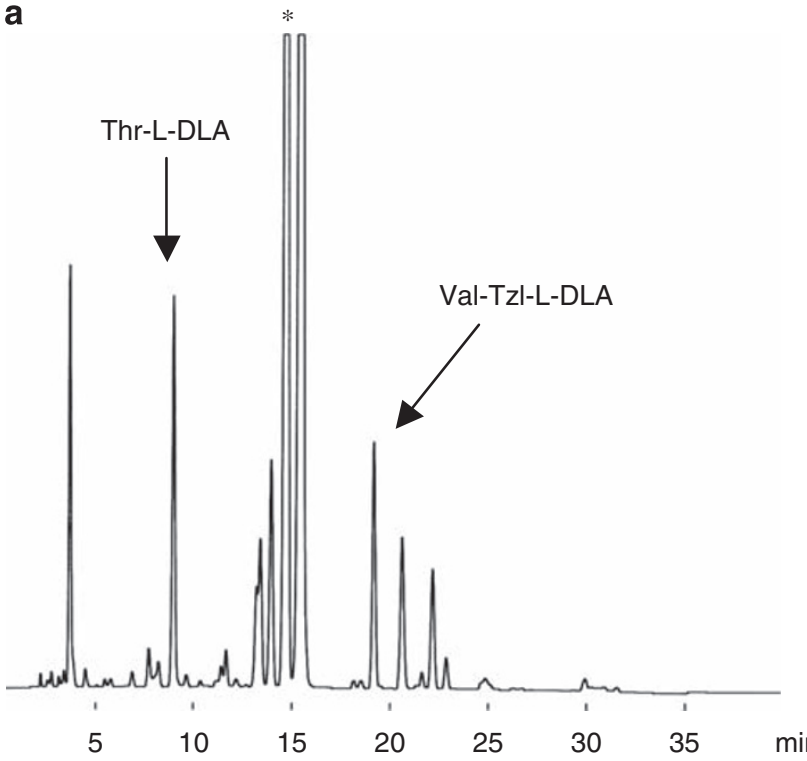

b

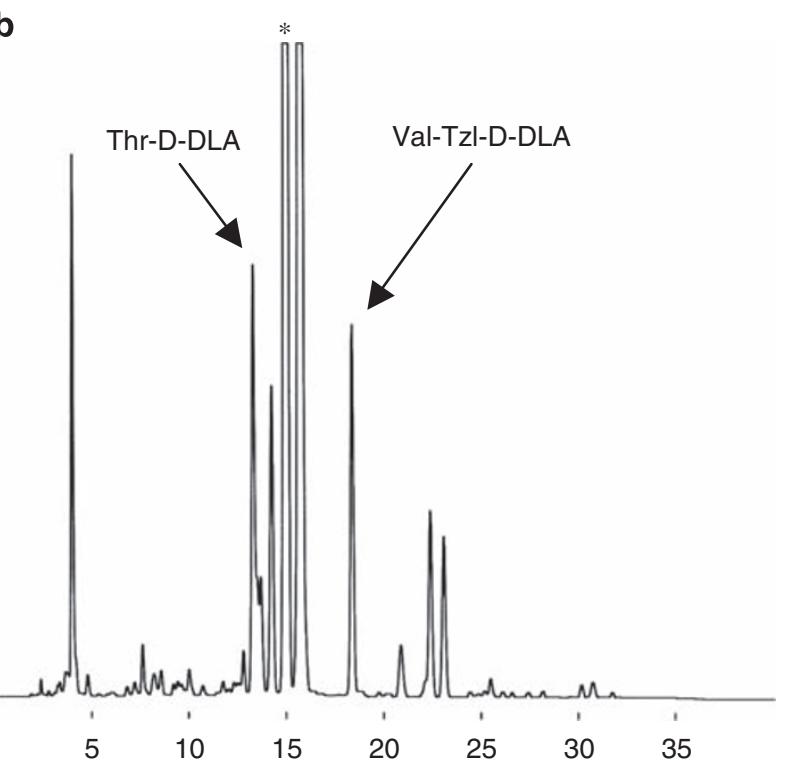

Figure 3 HPLC chromatograms of the DLA (2,4-dinitrophenyl-5-L-leucineamide) derivatives of the reaction mixture with (a) L-FDLA and (b) D-FDLA. Asterisks indicate residual reagent and related compounds.

\section{DISCUSSION}

During our continuing studies of biologically active compounds from pathogenic actinomycetes, we have isolated many biologically active compounds from the Nocardia species. According to a review by Bagley et al., ${ }^{6}$ the first thiopeptides produced by the Nocardia species to be identified were the nocathiacins, which belonged to series $e$ because they possessed a tetrasubstituted hydroxypyridine as the central heterocyclic domain. In this study, Nocardia pseudobrasiliensis (IFM 0757) obtained from a patient at the Health Center, University of Texas, was studied. The strain produced several active compounds, of which nocardicyclin A was characterized as a broth metabolite ${ }^{17}$ and nocardithiocin as a metabolite associated with the mycelium. 
A

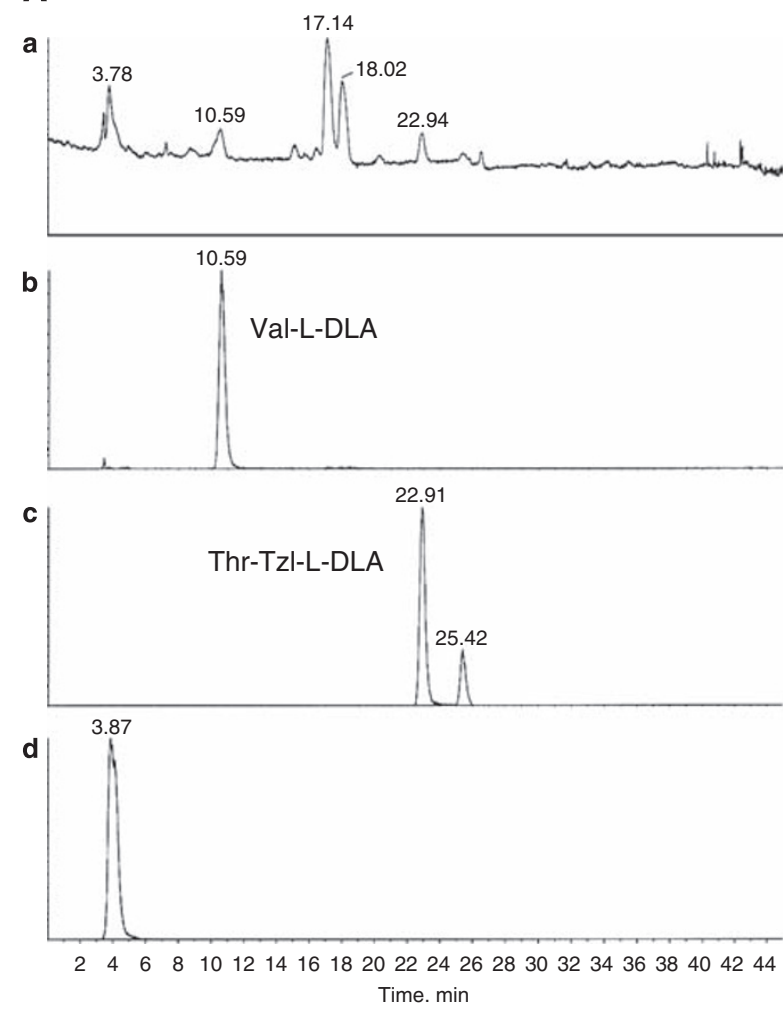

B

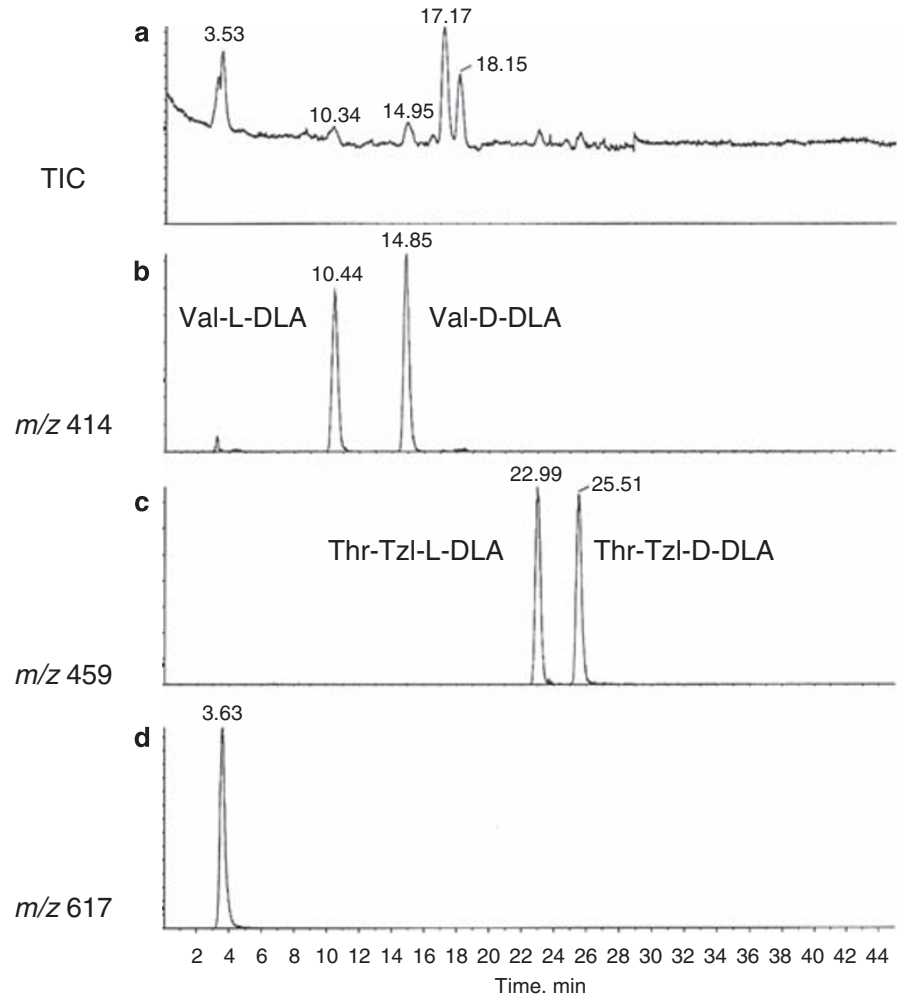

Figure 4 LC/MS data of the DLA derivatives of the reaction mixture with (A) L-FDLA and (B) L- + D-FDLA: (a) Total ion current chromatogram (TIC); (b) mass chromatogram at $\mathrm{m} / \mathrm{z} 414$; (c) mass chromatogram at $\mathrm{m} / \mathrm{z} 459$; (d) mass chromatogram at $\mathrm{m} / \mathrm{z} 617$.

Table 3 In vitro antimicrobial activity of nocardithiocin

\begin{tabular}{lc}
\hline Test organisms & MIC values $\left(\mu \mathrm{ml}^{-1}\right)$ \\
\hline Micrococcus luteus & $>133$ \\
Bacillus subtilis & $>133$ \\
Gordonia bronchialis & 0.03 \\
Corynebacterium xerosis & $<0.0078$ \\
Mycobacterium smegmatis & 0.062 \\
Nocardia asteroides & 0.062 \\
Escherichia. coli & $>133$ \\
Candida albicans & $>133$ \\
Cryptococcus neoformans & $>133$ \\
Aspergillus niger, & $>133$ \\
Paecilomyces variotii, & $>133$ \\
Trichophyton mentagrophytes & $>133$ \\
\hline
\end{tabular}

$2 \% \mathrm{MeOH}$ was added in broth to increase solubility of nocardithiocin.

The latter structurally belongs to the thiopeptide group of antibiotics and was classified into series $d$, because it has a 2,3,6-trisubstituted pyridine domain as shown in Figure 1. The identification of nocardithiocin was the second example of a thiopeptide from a Nocardia species. Nocardithiocin has a very similar thiopeptide nucleus to micrococcins $\mathrm{P} 1$ and $\mathrm{P} 2$ but differs in having a side chain terminating in an $\mathrm{O}$-methyl moiety (substructure A) and subtle differences to the thiopeptide ring substructures termed substructures $B$ and D. ${ }^{6}$ Although the absolute configurations of C-32, -46 and -47 were firmly determined to be $S, S$ and $R$, respectively, by advanced Marfey's method, those of C-23 and C-24 still remained unsolved. As men- tioned above, the compound was slightly sensitive to light and the cause of this instability is currently under investigation.

During our screening program of antimicrobial compounds, we have found and reported a new anthracycline type antibiotic called nocardicyclin. The structures were characterized by 1 - and 8 -methyl groups, a 10-carbonyl group and novel carbon-methylated amino sugar constituent. ${ }^{17}$ Although the antibiotics exerted a cytotoxic activity against leukemia in mice, they showed anti-Gram-positive bacteria, especially a strong antimycobacterial activity. We also reported a new siderophore and a benzonoid compound called asterobactin and nocaracins, respectively. ${ }^{18,19}$ Interestingly, both the siderophore and benzonoid compounds also showed strong antimycobacterial activity. These studies suggested to us that the Nocardia strains are useful sources for new antimycobacterial compounds. Indeed, this study showed that a pathogenic Nocardia strain produced a unique antibiotic, nocardithiocin. Although the reason for higher productivity of the antimycobacterial substances in Nocardia strains is not clear, it may be because of the high similarity of Nocardia to Mycobacterium strains regarding their physiological characteristics such as cell membrane or cell wall permeability. Both genera belong to a special bacterial group of acid-fast bacteria.

\section{METHODS}

\section{Instrumentation}

The NMR experiments were performed using JEOL-A400, -EXP-500 and -A600 spectrometers (Tokyo, Japan) in DMSO- $d_{6}$ or $\mathrm{CD}_{3} \mathrm{OD}$ at $40{ }^{\circ} \mathrm{C}$. The MS spectra were measured by JEOL-HX110 and JEOL-JMS-AX500 spectrometers for the FABMS and a Finnigan MAT TSQ700 (San Jose, CA, USA) for the ESI LC/MS. High-resolution MS spectra were obtained using a JEOL-HX110 under FAB 
Table 4 Antimicrobial activities of nocardithiocin against rifampicinsusceptible and -resistant Mycobaterium tuberculosis, and M. avium and $M$. intracellulare

\begin{tabular}{|c|c|c|c|c|}
\hline \multirow[b]{2}{*}{ Test organisms } & \multirow[b]{2}{*}{ Strain no. } & \multicolumn{3}{|c|}{$M I C\left(\mu g m^{-1}\right)$} \\
\hline & & Nocardithiocin & LVFX & RFP \\
\hline M. tuberuclosis & H37Rv & 0.78 & 0.39 & 0.39 \\
\hline \multirow[t]{13}{*}{ Rifampicin-susceptible } & 40 & 0.78 & 0.2 & 0.1 \\
\hline & 41 & 0.025 & 0.1 & $\leqq 0.006$ \\
\hline & 43 & 0.78 & 3.13 & 6.25 \\
\hline & 47 & 0.78 & 3.13 & 25 \\
\hline & 68 & 1.56 & 0.39 & 3.13 \\
\hline & 2 & 1.56 & 0.2 & 0.2 \\
\hline & 3 & 1.56 & 0.39 & 0.2 \\
\hline & 4 & 1.56 & 0.39 & 0.2 \\
\hline & 5 & 6.25 & 0.2 & 0.39 \\
\hline & 6 & 6.25 & 0.39 & 0.39 \\
\hline & 7 & 6.25 & 0.39 & 0.39 \\
\hline & 8 & 1.56 & 0.2 & 0.1 \\
\hline & 9 & 3.13 & 0.39 & 0.2 \\
\hline \multirow[t]{13}{*}{ Rifampicin-resistant } & 45 & 0.78 & 6.25 & $>100$ \\
\hline & 50 & 0.78 & 0.39 & $>100$ \\
\hline & 51 & 1.56 & 3.13 & 100 \\
\hline & 56 & 0.025 & 6.25 & $>100$ \\
\hline & 71 & $>6.25$ & 3.13 & $>100$ \\
\hline & 97 & 0.39 & 6.25 & $>100$ \\
\hline & 1 & 0.78 & 25 & 50 \\
\hline & 3 & 1.56 & 3.13 & $>100$ \\
\hline & 4 & 0.39 & 6.25 & $>100$ \\
\hline & 5 & 0.025 & 25 & $>100$ \\
\hline & 7 & $>6.25$ & 3.13 & $>100$ \\
\hline & 9 & 0.39 & 3.13 & $>100$ \\
\hline & 12 & 1.56 & 3.13 & $>100$ \\
\hline \multirow[t]{4}{*}{ M. avium } & $\mathrm{N}-357$ & $>6.25$ & 3.13 & 50 \\
\hline & $\mathrm{N}-458$ & $>6.25$ & 1.56 & $>100$ \\
\hline & $\mathrm{N}-444$ & $>6.25$ & 12.5 & 12.5 \\
\hline & $\mathrm{N}-472$ & $>6.25$ & 50 & 25 \\
\hline \multirow[t]{4}{*}{ M. intracellulare } & $\mathrm{N}-294$ & $>6.25$ & 12.5 & 3.13 \\
\hline & $\mathrm{N}-313$ & 1.56 & 6.25 & 0.78 \\
\hline & $\mathrm{N}-338$ & $>6.25$ & 12.5 & 3.13 \\
\hline & $\mathrm{N}-345$ & $>6.25$ & 25 & 3.13 \\
\hline
\end{tabular}

Abbreviations: LVFX, levofloxacin; MIC, minimum inhibitory concentration.

conditions. The UV spectra were recorded on a Shimadzu UV-2100 (Kyoto, Japan). The optical rotations were measured by a Jasco DIP-370 polarimeter (Tokyo, Japan). HPLC was carried out using the following two systems: pump; Shimadzu LC-9A, detector, Shimadzu SPD-10A (UV-VIS) or Shimadzu SPDM10A (diode array) and pump; TOSOH CCPS, detector; TOSOH UV-8020 (Tokyo, Japan).

\section{Fermentation}

The seed broth was prepared by inoculating mycelial elements of Nocardia pseudobrasiliensis IFM 0757 grown on the Brain Heart Infusion broth (BHI: Difco Laboratories, Detroit, MI, USA) in $10 \mathrm{ml}$ with $2 \%$ glucose in a $50 \mathrm{ml}$ Erlenmeyer shake flask. The culture was incubated on a rotary shaker at 250 r.p.m. for 4 days. Ten percent of the inoculum was transferred to a $500 \mathrm{ml}$
Erlenmeyer shake flask containing $100 \mathrm{ml}$ of the production medium (two times concentrated nutrient broth medium, Difco Laboratories) and the culture was incubated on a rotary shaker at 250 r.p.m. for 7 days.

\section{Isolation}

After centrifugation of the culture broth (21), the mycelia were subjected to extraction by $\mathrm{MeOH}$ with stirring. The extract was evaporated and the residue was subjected to liquid-liquid extraction with EtOAc and water. The EtOAc fraction was evaporated and the residue was separated by the following HPLC procedure under dark conditions to provide nocardithiocin in a pure state (10.5 mg): column, Cosmosil 5C18-ARII $(250 \times 10 \mathrm{~mm}$ ID, Nacalai Tesque, Kyoto, Japan); mobile phase, $\mathrm{MeOH}$ : $0.01 \%$ TFA=52:48; flow rate, $1.0 \mathrm{ml} \mathrm{min}^{-1}$; detection; $254 \mathrm{~nm}$.

\section{Advanced Marfey's method}

One milligram of nocardithiocin was dissolved in $500 \mu \mathrm{l}$ of $6 \mathrm{M} \mathrm{HCl}$, and then heated at $110^{\circ} \mathrm{C}$ for $1 \mathrm{~h}$ under nitrogen. The reaction solution was evaporated to dryness and $150 \mu \mathrm{l}$ of water and $50 \mu \mathrm{l}$ of $\mathrm{MeOH}$ were added. The solution was divided into two portions and $20 \mu \mathrm{l}$ of $1 \mathrm{M} \mathrm{NaHCO}$ and $100 \mu \mathrm{l}$ of $1 \%$ L-FDLA (1-fluoro-2,4-dinitrophenyl-5-L-leucineamide) or D-FDLA acetone solution were added to each portion. The solution was heated at $40{ }^{\circ} \mathrm{C}$ for $1 \mathrm{~h}$ and the reaction was quenched by the addition of $20 \mu \mathrm{lof} 1 \mathrm{M} \mathrm{HCl}$. After dilution with $220 \mu \mathrm{l}$ of acetonitrile, 0.1 and $1 \mu \mathrm{l}$ of the DLA derivatives of all the samples were analyzed by the following HPLC and ESILC/MS, respectively: column; TSK gel ODS- $80 \mathrm{Ts}(150 \times 4.6 \mathrm{~mm}$ ID, TOSOH $)$, mobile phase; acetonitrile: $0.05 \%$ TFA, gradient condition; acetonitrile $30 \rightarrow 70 \%$, flow rate; $1.0 \mathrm{ml} \mathrm{min}^{-1}$, detection; $340 \mathrm{~nm}$, column; TSK gel ODS- $80 \mathrm{Ts}(150 \times 2 \mathrm{~mm} \mathrm{ID}$, TOSOH), mobile phase; acetonitrile: $0.05 \%$ TFA, gradient condition; acetonitrile $30 \rightarrow 70 \%$, flow rate; $0.2 \mathrm{ml} \mathrm{min}^{-1}$, split ratio; $1: 40$, detection; MS (positive ion mode).

\section{Antimicrobial activity measurement}

The antimicrobial activities were determined by a method described earlier ${ }^{20}$ using the microbroth dilution method, except for the determination of MIC values against the slowly growing mycobacteria. The antimicrobial activities against the slowly growing mycobacteria were determined by the agar dilution method using the MIDDLEBROOK 7H10 agar medium (BD, Difco). Inocula were prepared by incubation of the Mycobacterium species in MIDDLEBROOK (7H9) liquid medium at $37^{\circ} \mathrm{C}$ for $2-3$ weeks in a $5 \% \mathrm{CO}_{2}$ incubator. After adjustment of the cell concentration by the optical density measurement, the diluted cell suspensions were inoculated onto the MIDDLEBROOK 7H10 agar medium containing various drug concentrations. After incubation at $37^{\circ} \mathrm{C}$ for 14 days (for Mycobacterium avium and Mycobacterium intracellulare) and 21 days (for M. tuberculosis), the MIC values were determined. The M. tuberculosis H37Rv strain was used as the standard strain. Rifampicin (REF; Sigma-Aldrich Co., Tokyo, Japan) and levofloxacin (Daiichi Seiyaku Co., Tokyo, Japan) were used as the reference drugs in this study.

\section{ACKNOWLEDGEMENTS}

This work was partially supported by a Grant from Daiichi Pharmaceutical Co. (presently Daiichi-Sankyo Pharmaceutical Co.) Ltd, Chiba, Japan.

1 Bérdy, J. Bioactive microbial metabolites: a personal view. J. Antibiot. 58, 1-26 (2005).

2 Beaman, B. L. \& Beaman, L. Nocardia species: host-parasite relationships. Clin. Microbiol. Rev. 7, 213-264 (1994).

3 Kageyama, A. et al. Nocardial infections in Japan from 1992 to 2001, including the first report of infection by Nocardia transvalensis. Eur. J. Epidemiol. 19, 383-389 (2004).

4 Tsuda, M. et al. Brasilibactin A, a cytotoxic compound from actinomycete Nocardia brasiliensis. J. Nat. Prod. 68, 462-464 (2005).

5 Komatsu, K., Tsuda, M., Tanaka, Y., Mikami, Y. \& Kobayashi, J. SAR studies of brasilicardin A for immunosuppressive and cytotoxic activities. Bioorg. Med. Chem. 13, 1507-1513 (2005).

6 Bagley, M. C., Dale, J. W., Merritt, E. A. \& Xiong, X. Thiopeptide antibiotics. Chem. Rev. 105, 685-714 (2005). 
7 Holmes, D. J., Caso, J. L. \& Thompson, C. J. Autogenous transcriptional activation of a thiostrepton-induced gene in Streptomyces lividans. EMBO J. 12, 3183-3191 (1993).

8 Mai, T. et al. Productivity of antimicrobial substances in pathogenic actinomycetes Nocardia brasiliensis. Microbiol. Cult. Coll. 13, 103-108 (1997).

9 Yun, B. S. \& Seto, H. Promoinducin, a novel thiopeptide produced by Streptomyces sp. SF2741. Biosci. Biotechnol. Biochem. 59, 876-880 (1995).

10 Leet, J. E. et al. Nocathiacins, new thiazolyl peptide antibiotics from Nocardia sp. II. Isolation, characterization, and structure determination. J. Antibiot. 56, 232-242 (2003).

11 Rodríguez, J. C., Holgado, G. G., Sánchez, R. I. S. \& Cañedo, L. M. Radamycin, a novel thiopeptide produced by Streptomyces sp. RSP9. II. Physico-chemical properties and structure determination. J. Antibiot. 55, 391-395 (2002).

12 Muramatsu, I., Motoki, Y., Aoyama, M. \& Suzuki, H. Amino acids and derivatives of thiazole-4-carboxylic acid as constituents of thiopeptin B. J. Antibiot. 30, 383-387 (1977).

13 Fujii, K. et al. A nonempirical method using LC/MS for determination of the absolute configuration of constituent amino acids in a peptide: elucidation of limitations of Marfey's method and of its separation mechanism. Anal. Chem. 69, 3346-3352 (1997).
14 Fujii, K., Ikai, Y., Oka, H., Suzuki, M. \& Harada, K.-I. A nonempirical method using LC/MS for determination of the absolute configuration of constituent amino acids in a peptide: combination of Marfey's method with mass spectrometry and its practical application. Anal. Chem. 69, 5146-5151 (1997).

15 Fujii, K. et al. Simultaneous detection and determination of the absolute configuration of thiazole-containing amino acids in a peptide. Tetrahedron 58, 6873-6879 (2002).

16 Harada, K.-I. et al. Application of D, L-FDLA derivatization to determination of absolute configuration of constituent amino acids in peptide by advanced Marfey's method. Tetrahedron Lett. 37, 3001-3004 (1996).

17 Tanaka, Y., Gräfe, U., Yazawa, K., Mikami, Y. \& Ritzau, M. Nocardicyclins A and B: new anthracycline antibiotics produced by Nocardia psedobrasiliensis. J. Antibiot. 50, 822-827 (1997).

18 Tsuda, M. et al. Nocaracins A-C, and brasiliquinone D, new metabolites from the actinomycete Nocardia brasiliensis. J. Nat. Prod. 62, 1640-1642 (1999).

19 Nemoto, A. et al. Asterobactins, a new siderophore group antibiotic from Nocardia asteroides. J. Antibiot. 55, 593-597 (2002).

20 Kaneda, S. et al. Biological activities of newly prepared saframycins. J Antibiot. 40, 1640-1642 (1987). 